\title{
Integrated approach for risk management in servitization decision-making process
}

\author{
Sarra Dahmani \\ SKEMA Business School, Université Côte d'Azur, Paris, France \\ Xavier Boucher \\ Mines Saint-Etienne -Institut Fayol, Université Clermont Auvergne, \\ Saint-Etienne, France \\ Didier Gourc \\ IMT Mines Albi - Centre Génie Industriel, Université de Toulouse, Albi, France \\ Sophie Peillon \\ Mines Saint-Etienne -Institut Fayol, Université de Lyon, \\ Université Lumiére, Université Jean Monnet, Saint-Etienne, France, and \\ François Marmier \\ IMT Mines Albi - Centre Génie Industriel, Université de Toulouse, Albi, France
}

\begin{abstract}
Purpose - The paper proposes an innovative systemic method helping decision-makers to control servitization transition process, through decision process risk diagnosis.

Design/methodology/approach - The proposed method is based on the modeling of decision processes and risk identification and analysis. This method was based on an action-research approach, in close relationship with two companies (SMEs). The paper develops the feasibility experiment at Automelec company.

Findings - The method was successfully implemented and delivered concrete diagnosis results.

Research limitations/implications - The generalization of the applicability of the method needs to be tested on several different cases.

Practical implications - The first practical implication is related to the efficiency of the method to help decision-makers in a servitization context to limit uncertainty and get a global view of the weaknesses of their decision-making process, it raises their awareness about servitization transition for their companies. Furthermore, the method also helps to explain the strategy of a servitization transition. It enhances the level of maturity of the decision process of the company, and can be used as a training/learning tool for managers.

Social implications - The results brought by the research contribute to give the decision-making boards for organization living a servitization transition and especially SMEs a better control over the servitization decision process and related risks, which will increase the economic stability of the company and its vision over long, medium and short horizons. This will bring positive impact on the overall economic and social environment and networks of the servitized SME, and enhance the confidence of coworkers, subcontractors and clients.

Originality/value - The first originality of the paper is related to the new way of considering risk, not only as an analysis criterion but as the central driver in steering a strategic transition for the company, such as servitization. The second originality of the study is about assessing risk occurrence over a decision-making process through decision reliability and decision confidence.
\end{abstract}

Keywords Decision making process, Servitization, Risk occurrence 


\section{Introduction}

In a business world marked by customization-oriented competitiveness, servitization is currently spreading throughout all levels of the industrial economy as an organizational capability and process to better create mutual value through a shift from selling products to selling Product Service Systems (PSS) (Bustinza et al., 2015; Baines et al., 2007; Lightfoot et al., 2013). Servitization, PSS concepts and experiments have spread during the last decades in academic and practitioner communities (Hou and Neely, 2013), with a recent renewed interest through the development of smart PSS and digital servitization (Oluwafemi and Laseinde, 2020; Wang et al., 2018). In many advanced economies, servitization is considered as a development approach able to provide opportunities to achieve sustainability, improve enterprise competitiveness, and better satisfy customer needs (Doualle et al., 2020; Vandermerwe and Rada, 1988). Nevertheless, this paradigm shift requires questioning the business objectives and overall functioning of companies. PSS are not based only on technical aspects; organizational aspects are also strongly involved, which makes the implementation in industrial businesses complex (Cook et al., 2006; Rabetino et al., 2017). Clearly, transition from product manufacturer to service provider constitutes a risky managerial challenge (Oliva and Kallemberg, 2003; Nudurupati et al., 2016; Rabetino et al., 2017). It involves the company in a dynamic and complex decision-making process due to the high level of uncertainty related to value proposition (Murillo-Coba et al., 2019), customer targeting and satisfaction, and paradigm shifts for employees, marketers or sales.

Thus, scientific advances over the past years have emphasized and formalized servitization, or more recently digital servitization, as a transition process both at strategic and organizational levels. However, a literature gap remains on two complementary issues which could lead to deeper advances on advanced methodologies for transition management. First, the complexity of the numerous and interactive decisional situations and processes embedded in the transition is poorly analyzed from a scientific point of view (Weeks and Benade, 2015; Ricciardi et al., 2016; Kowalkowski et al., 2012; Crowley et al., 2018). The existing literature lacks dedicated in-depth decision support models able to represent the complexity of the system and to help strategic transition planning (Lenka et al., 2018; Coba et al., 2019; Rabetino et al., 2017; Burton et al., 2016; Lightfoot et al., 2013; Raddats et al., 2019). Second, even if the transition is clearly associated to important managerial risks, a wellformalized and structured method to address risk management throughout the whole servitization process is still missing. It remains necessary to provide decision-makers with methods and tools to anticipate decisional strategic and operational risks merging all along the full transition process, to evaluate them at distinct decision levels, then to compare alternative strategies of risk mitigation. Even though the literature largely advocates the transition towards services, many firms struggle to achieve the suggested benefits (Vladimirova, 2012; Rabetino et al., 2017; Raddats et al., 2019; Lenka et al., 2018; AlonsoRasgado et al., 2004; Boughnim and Yannou, 2005; Meïer et al., 2011; Shimomura and Akasaka, 2013; Seiringer, 2013; Boucher and Medini, 2016; Zhang et al., 2019). The need for well-structured methods to help companies managing the strategic transition is becoming capital, and the literature lacks generic approaches able to absorb the complexity of the process and to be directly deployable by practitioners. Focusing on the dual dimensions (1) "decision situations and processes" and (2) "risk management" should provide important insights for industrial decision-makers in charge of implementing servitization strategies. Therefore, in this paper we address the research question, "How to integrate risk in servitization decision-making process for an industrial company?"

We aim to discuss an innovative approach to consider risks in servitization processes. The main purpose is to provide a method helping decision-makers in controlling servitization transition process, through decision risk diagnosis. The approach considers servitization through the complex decision-making process required to manage the business model 
transition. The paper proposes a systemic diagnosis method to help managers' understanding of which decisions carry a high risk of failure which would result in a significant potential loss of performance for the company and how it would be possible to reduce the risk level. This contribution builds a formal way to model and diagnose servitization decision-making processes, within a manufacturing company. This diagnosis is expected to increase awareness of decision-makers on servitization decisional weaknesses, in order to make possible adequate remediation measures.

This paper contains five main parts: the first one gives an overview about literature on servitization in relation to risk management; the second part explains our methodological positioning; in the third part we define the conceptual framework we propose and the different estimators of risk; the fourth presents the illustration and feasibility validation of the method through a case study of a French enterprise; and in the fifth part we discuss the results.

\section{Literature}

The paper addresses two main limits of the current literature on the management of servitization, which are further analyzed in the following state of the art:

(1) The factors of complexity for the management of servitization transformation processes. The question is to understand what is the available scientific background on this issue and what are the main weaknesses to support consistently managerial decisions, all along the transition process;

(2) The scientific advances on risk management approaches, able to address the specificity and complexity of servitization decision-making situations.

\subsection{Servitization: a complex transformation for the manufacturing firm}

To survive in developed economies it is widely assumed that manufacturing firms can rarely remain pure manufacturing firms (Neely, 2007). Servitization represents then a possible alternative to enlarge the core business of industrial firms by shifting from a pure product supplier to PSS supplier (Burton et al., 2016). Nevertheless, servitization brings about a systemic transformation of the strategic pillars of the company, marked by a high level of uncertainty. It is a complex transition for the industrial firm. It requires a complex transformation process (Vladimirova, 2012; Burton et al., 2016; Raddats et al., 2019; Lenka et al., 2018).

Scientific literature underlines three sets of strategic factors which encourage manufacturing companies to adopt a servitization strategy: financial, strategic and marketing factors (Oliva and Kallenberg, 2003; Gebauer and Friedli, 2005; Baines et al., 2009; Gebauer et al., 2010). The complex transformation from product supplier to service supplier leads managers to rethink the enterprise strategy (Classen and Friedli, 2019), internal processes and capacities as well as its external networks (Zambetti et al., 2019). The maturity of the company on these different decision problems can be different; this will influence the perception of the uncertainties related to each dimension: strategy, capacities and processes, and networks.

Services require a change in organizational principles, structures and processes for the manufacturer. Adopting a servitization strategy also brings important cultural and managerial challenges (Oliva and Kallenberg, 2003; Slack, 2005; Baines et al., 2009). In manufacturing industries, employee sense-making regarding the concept of servitization and how they react to servitization may be bounded by the constraints of a product-centric manufacturing heritage, despite the stated strategic direction being focused on the end state of servitization (Crowley et al., 2018). In the process of servitization, internal managerial tensions (Burton et al., 2016) may result in a firm's stated servitization intent being at odds with the intent of many individuals within the organization who want to maintain the 
product-based business model (Crowley et al., 2018). Alignment between the strategy and organization changes is essential in the shift to a service-led business model (Kowalkowski et al., 2015). Coherence of intentionality among the individuals in an organization has been identified as a success factor for entrepreneurial organizations, without which there is "inefficient communication, inconsistent decisions, and counterproductive conflict, thereby contributing to the vulnerability of the venture" (Bird, 2015). Even if servitization transition is considered as a chance to improve competitiveness, its systemic complexity remains problematic and makes it difficult to be adopted and integrated to existing offerings (Story et al., 2015; Weeks and Benade, 2015). According to Neely (2007) how manufacturing firms servitize and what servitization involves as a process, remain fundamental questions.

To help understand the complexity of the servitization system, literature has analyzed the possible ways to decompose it, to represent it through a transition continuum (Oliva and Kallemberg, 2003), through transforming paths or trajectories (Peillon et al., 2015) or through decision-making processes (Dahmani et al., 2016; Crowley et al., 2018). To understand servitization, Story et al. (2015) predict that in reality, taking a single firm-level view may not be sufficient; there is a need for the development of contextual specific understanding of how firms approach their "servitization journey" (Story et al., 2015). They deduce that servitization transition can be considered more as an education, in which firms progressively develop new capabilities and retain product-related capabilities. Similarly, individuals also learn new skills and knowledge while maintaining their previous learnt capabilities. Firms should focus efforts on building understanding in a number of key areas, as part of determining how their journey would be: the transition requires taking complex decisions on the specificities of servitization for each company business model (Kowalkowski et al., 2012; Crowley et al., 2018). In this perspective, Oliva and Kallenberg (2003) propose an interesting way to explain servitization transition for manufacturers. They define a continuum from pure product offering to pure services, the enterprise can then identify its positioning according to this generic continuum. Various classifications or configurations of PSS are then proposed (Behrend et al., 2003; Tukker, 2004). Johansson and Olhager (2006) propose a complementary framework to help analyzing the relevance and consistency of alternative product service strategies. Crowley has introduced the notion of strategic intent for servitization processes (Crowley et al., 2018).

Literature on servitization converges to conclude that servitization brings "complex decision-making situations" for the industrial company (Dahmani et al., 2016; Crowley et al., 2018; Kowalkowski et al., 2012). Ensuring the systemic long coherence and balance among all the decisions is not simple to achieve. Literature revealed a lack of structured, reusable approaches to explain, model and rationally manage this complex decision-making process.

One of the particularities of servitization studies is the scarcity of completed experiments. In fact, the high innovation level necessary and the scarcity of full reports on complete deployments of this transition in real business cases do not allow the building of data bases by which we could carry out reliable statistical studies. In addition, there is the innovative transition process and the particularity of each specific strategic path. This remains a rather new strategic approach where industrial actors and researchers discuss to derive generalized guidelines or at least possible or practical ones.

This research includes a definition and model of servitization decision-making processes, built to facilitate risk analysis during the transition project. The notion of risk is introduced in the next section, before developing the formalization of this servitization decision-making process in Section 3.

\subsection{Risk in servitization}

Literature studying risk management in servitization transition is very limited. Literature about servitization has treated the concept of risk indirectly through barriers and 
opportunities analysis (Mont, 2004). Servitization barriers are considered as mainly related to value creation challenges and possible scenarios for the business model (Baines et al., 2009). Risk related to service has been treated in literature; it mainly refers to coordinating issues between business ability and market expectations on one hand and organizational strategy, design and development on the other hand (Sawhney et al., 2004). Service types can also affect considerably servitization performance (Benedettini et al., 2013). Studies oriented towards risk assessment for service innovations attempt to quantify risk occurrence probability and extent of losses in risk matrices, in order to propose risk management plans (Schmitt et al., 2013).

We can conclude that risk management approaches and systems don't represent a focal positioning for servitization literature. However, the concept of risk management is central to practitioners, especially for companies trying to make the servitization transition.

We consider then the importance to define basics for risk management; for this we referred to a general literature on risk modeling and risk management.

In risk analysis modeling, it is important to differentiate risk factors from risk impacts. According to Gourc (2006) (Figure 1), every risky situation is due to a combination of causes (origins) brought together in an occurrence area, and generates a set of impacts (effects) brought together in an impact area. The risk event represents the intersection between both of the distinct areas (Figure 1). We adapt the Gourc (2006) model to define risk in servitization decision-making processes. Risk in servitization decision processes represents the possibility for a decision-maker to commit a decision failure which can be represented through an inadequate decision choice, the occurrence of which can lead to negative consequences for conducting the process (consequences in Figure 1) as well as for the planned objectives of value creation (effect or impacts in Figure 1).

For the implementation of servitization strategy in industrial firms, we consider the existence of three types of risk factors:

(1) Risk Factors, which are internal to the company and to the servitization decisionmaking process and concern the decisions involved in the servitization decision process;

(2) Risk Factors which are internal to the company but external to the servitization decision-making process. They are related to the initial situation of the company, its fragility, existing networks, level of maturity.

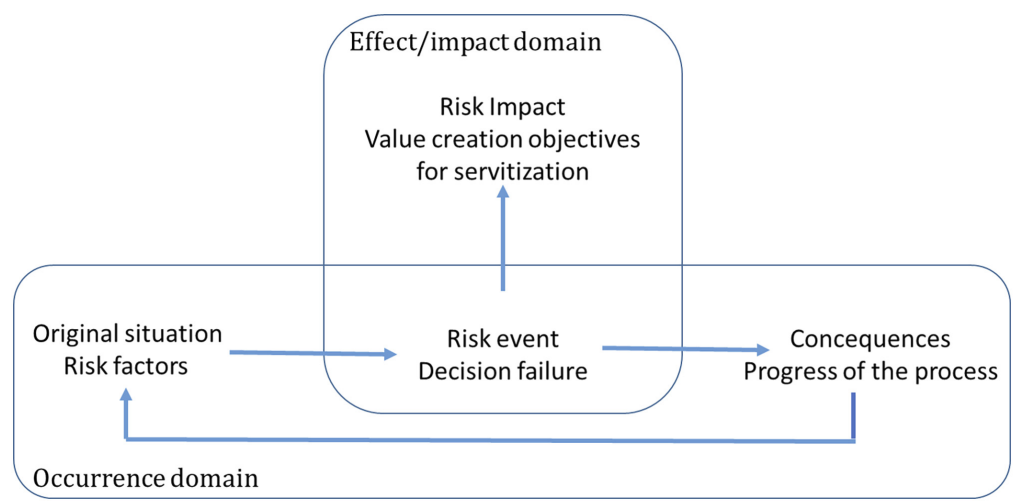

Figure 1 .

Definition of risk in servitization process (adapted from Gourc, 2006) 
(3) Risk factors which are external to the company and external to the servitization decision-making process: they are related to the company's external environment, and refer to the enterprise environmental factors (PMBok).

Internal risk factors can be identified by diagnosis approaches and included in the company's control perimeter. External risk factors are related to the company's external environment. They cannot be controlled by the company which most of the time can only deal with them.

Differentiating the risk impacts from the risk consequences allows to distinguish between the consequences on accomplishing the servitization process itself: for example, how failed decisions can spread and become risk factors for other decisions; and the impacts related to achieve value creation objectives thought servitization transition.

Considering our purpose to provide an approach to control servitization decision-making processes, we focus specifically on analyzing the occurrence area, and more precisely internal risk factors to the company and to the servitization decision-making process. This enables us to take into account mainly the aspects that can be controlled by decision-makers. We consider risk occurrence as the result of a systemic association of a set of factors.

This is based on the decomposition of the reference decision process we define (cf. 3.1). We consider that working on the quality of the decision process allows ultimately improving the quality of decision choices.

The risk event is represented through decision failure that consists in making inadequate decision choices and affects many decisions of servitization processes. It may be due to insufficient information or inadequate earlier decision choices.

The realization of decision failure may result in negative effects on achieving the strategic value creation objectives that were intended by the enterprise managers.

Using these basic definitions, and based on the reference model of servitization decisionmaking processes (cf. Section 3) we define a global approach for decision process risk diagnosis for servitization developed in Section 4. The research methodology approach we adopted is introduced in the next section.

\section{Research strategy and methodological approach}

The aim of this study is to provide decision-makers with a reliable and operational decision support to steer the servitization process by relying on an integrated risk diagnosis approach.

Our methodological approach is notably based on the importance of cooperation between researchers and practitioners in the construction of research problems and their resolution. Our aim is to produce through this research a useful approach for practitioners able to improve the level of awareness and control of the servitization transition and the overall success of the servitization project.

We have identified two levels of the methodology we adopt: a first strategic level developed in this section aims to explain how we have created the diagnosis method and the different associated tools/estimators; the second level (detailed in Section 5.2) aims to detail the operational research methodology we have used to make the feasibility experiment of the diagnosis method we created.

Cooperation between researchers and practitioners has always been controversial. In order to overcome the gap, Van-de-Ven (2007) proposed the position of engaging scholarship to bring together researchers and practitioners through a pluralistic and collective vision of research with the aim of creating research rooted in theory and significant for practitioners. Other approaches are also part of this vision, such as action research which requires, in the construction of the research, the involvement of the researcher as well as the actors involved in the experimentation (Barbier, 1996). As our work focuses on the decision-making dimension, we position this research in the pluralistic perspective that affirms the importance 
of collaboration between academics and practitioners in the design and implementation of research.

The research strategy we adopt implies a strong participation of the researcher in the life of the company. This research can thus be considered as an action-research (Lewin, 1951), because of the important involvement of the researcher (who can influence certain decisionmaking processes of the company's decision-makers), but also the important correlation between theory and practice for the construction of the various tools (reference decision model and evaluation estimators). This study is part of a French ANR multidisciplinary research project called ServInnov (Sustainable Innovation through Service). ServInnov brings together different actors from the academic field, who, according to their work and contributions, are considered as experts in the field of servitization for industrial enterprises. The project involved practitioners from industrial fields as well as managers of industrial enterprises or consultants in permanent relations with companies. We defined the research method to take advantage of the ServInnov context and capture the maximum of richness from the consortium (both academic and industrial fields) to help improving decision-making processes.

This methodological approach includes three different stages (Figure 2) corresponding to complementary objectives and expected results:

(1) A first stage of research consists in building the conceptual framework based on literature about servitization, decision theory, decision system modeling and risk management. Two key elements of the framework were defined: (1) a generic model of the decision-making process associated to servitization, called the Reference Model (this has been detailed in a Dahmani et al., 2016, and we propose a synthetic description in Section 3.1) and (2) a set of decision process estimators useful to later define risks. In this stage the literature provided the initial inputs to identify the conceptual bases and uses of the method, as well as the theoretical objectives that will be useful to our approach. Then a rigorous formalization of the models was developed, using dedicated modeling approaches (cf. Section 3.1 and 4.1). The

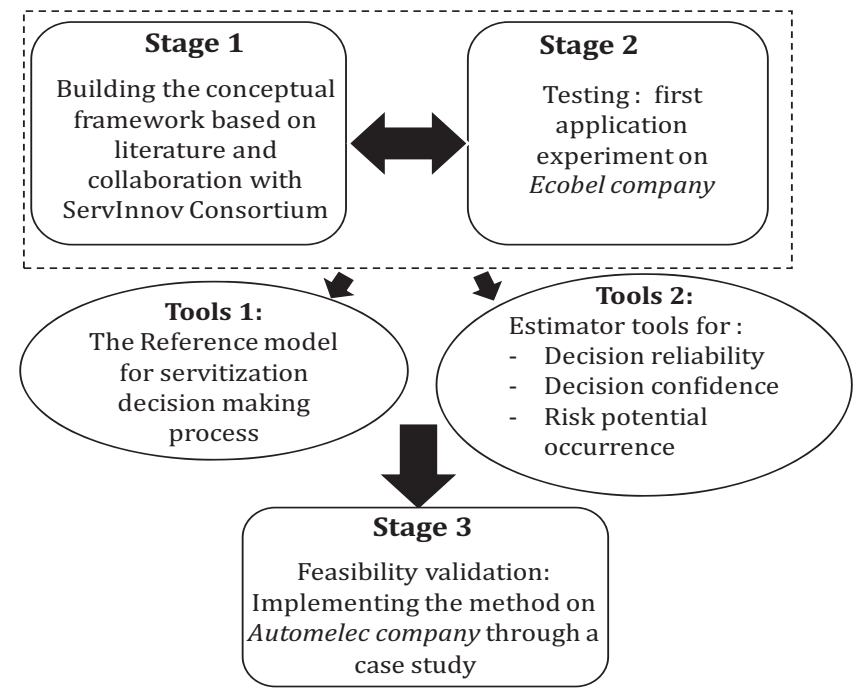

Figure 2.

Methodological approach 
reference model and the risk indicators were then discussed through focus groups with experts in the ServInnov consortium. At this stage, a first validation was made of the Reference Model for servitization decision-making processes and associated estimators. The models were confronted with the opinions of external experts (scientists and industrialists present in the ServInnov network), in order to adapt the proposal to the different points of view, and to make improvements. For this, we organized four validation focus groups of three hours each, covering various complementary validation themes. The contents of these scientific meetings have been recorded and transcribed.

(2) A second stage of the research methodology consists in a first testing of the feasibility experiment. It has the objective to test the model on a first simple case, and to give valuable feedbacks for improvements. This was made on a small French company case named Ecobel. The case experiment has helped to give a first validation for the method and to give helpful insights to improve the model and especially to improve the operational aspects for data collecting, and further on how to limit the bias in interpreting decision-makers' explanations of their strategy. This first experiment allowed also to adapt some vocabulary used in the reference model. The data collecting for Ecobel was made through four semi-conducted interviews of two hours each. The result of the analysis were discussed with the leader of Ecobel. Feedbacks from this experiment have helped to improve the method. We can consider that this first case study has contributed to the creation of the method.

(3) A third stage is about implementing the method on a second real case to finally validate its feasibility. The reference model and indicators are instantiated according to a real medium sized company. Case studies are appropriate tools for exploring subjects that are difficult to replicate (Eisenhardt and Graebner, 2007; Siggelkow, 2007). This third stage of the methodology is based on a case study logic (Gombault, 2005; David, 2003). This step is fundamental to give a final validation for the method developed and to understand the valuable results it can bring. Data collecting was made through semi directed interviews and as well as informal meetings. We develop later in Section 5.2 the details about the operational methodology for data collection and analysis process. The second case can be considered as a validation step for the method (cf. 5.2).

\section{Servitization: a decision-making process}

The following sections develop a formalism to identify and characterize the servitization decision-making process to make the link with risk analysis.

Decision-making processes can be understood in the larger context of decision systems. A "decision-process" is constituted by sets of decision rules, procedures structured throughout more or less structured "decision-activities." Decision processes contribute to maintain a consistent level of performance of an operational system, or to manage its efficiency improvement when necessary. Decisions are related to a multitude of parameters, describing the organization of the system and its relationship with the environment (Gourc, 2006). We consider the servitization decision-making process as a set of decision parameters, activities and processes, structured within several complementary decisional domains, as we have underlined. Each of these domains embeds several decision sub-processes, which still have to be clearly identified and described through a specific modelling formalism.

On the basis of a bibliographic analysis (Oliva and Kallenberg 2003; Baines et al., 2009; Gebauer and Kowalkowski, 2012; Bustinza et al., 2015; Baines et al., 2007; Lightfoot et al., 2013; Cook et al., 2006; Rabetino et al., 2017) and experience feedbacks from different leaders of 
industrial companies moving through a servitization transition, the authors propose to decompose the global servitization process into three decisional domains, covering complementary dimensions and natures of the decisions to be taken. These three domains (later formalized as Macro-Processes, MP) cover the following issues: (1) the PSS technical design; (2) the PSS business model transformation; and (3) the organizational changes, required to support the PSS implementation. Decision-makers are confronted with the systemic nature of these decisional domains, their complex interactions and dynamic evolution over time. The full justification of this structure into three domains can be found in previous publications (Dahmani et al., 2013; Dahmani et al., 2016). They are developed in the next section.

\subsection{Decision making-process for servitization: proposition of a reference model}

For a general understanding of further developments on risk analysis, the authors synthesize, in this section, the approach they have defined to model servitization decision-making process. This approach re-uses formalisms from the field of decision-system modelling (Doumeingts et al., 1992; 2000; Vernadat, 2002; Chen et al., 2008) and has been specified in detail in Dahmani et al. (2016). This modelling approach is first based on two decomposition axes: vertical and horizontal (Figure 3):

(1) The vertical axis is related to the temporality of decisions. Strategic, Tactical and Operational decision levels are considered;

(2) The horizontal axis relates to the decomposition of the various dimensions/natures of the decisions involved. These various dimensions are called Macro-Processes (MP). The approach considers the three decision domains previously mentioned as MP: MP1-PSS technical design; MP2-PSS business model transformation; MP3Organizational changes.

Complementary to these two decomposition axes, two additional concepts are necessary to understand the modelling approach: the notions of (1) Critical Decision Processes (CDP) that represents a sub-component of a MP and comprises decisions made on a specific time

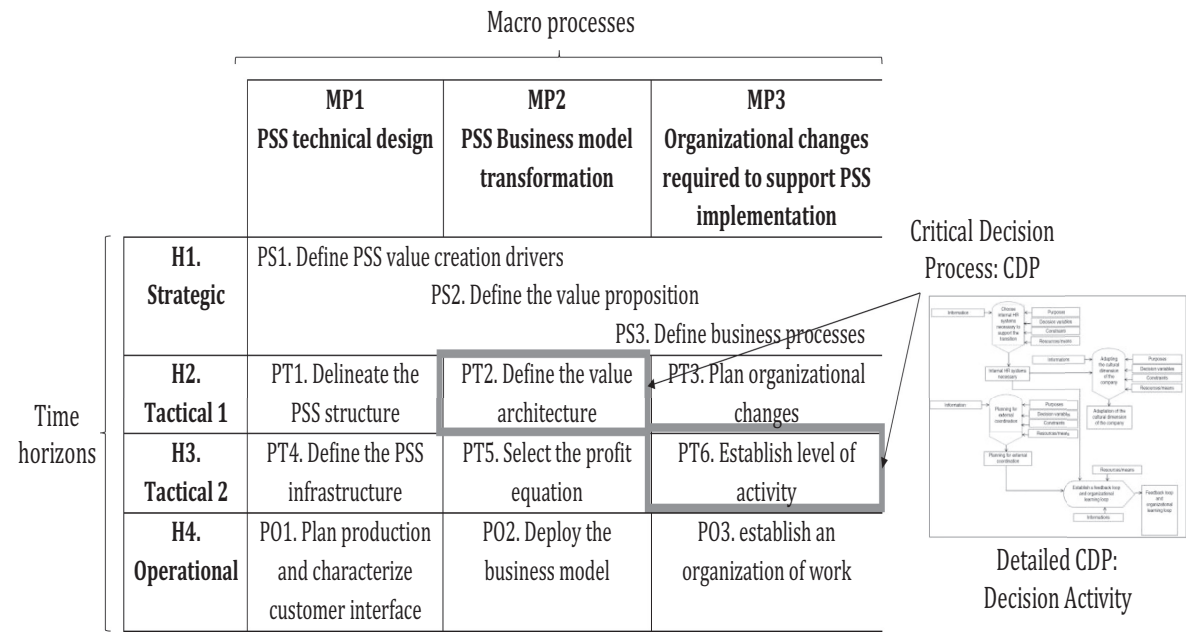

Figure 3.

Reference model for Servitization decision making process 
Macro-process (MP)

Critical Decision Process (CDP)

Decision Activity (DA)
An MP corresponds to a functional decisional domain, and embeds a coherent set of decisions related to the company's overall goals, and functional domain

A CDP is a sub-component of a MP and comprises decisions made on a specific time horizon (strategic, tactical 1 or tactical 2 or operational). It embeds a set of decision-making activities, and its outputs are likely to have a significant impact on the overall transition process considered

A DA represents a basic/elementary decision. In the servitization decision-making process DA represents the finest decomposition level of the system. Any DA transforms incoming data elements (inputs), into one or more outputs consisting in new pieces of information, then available for other decision processes. According to GRAI formalism used, every DA is modeled by the decision-making characteristics $\mathrm{Ci}$. DA are divided into two categories: DA-D and DA-E. Decisionmaking activity (DA-D) is represented by seven $\mathrm{Ci}$ (input, output detailed; information; constraints decision variables (VD), and purpose) and an Execution decision activity (DA-E) characterized through five elements (input, output detailed; information; means; actors). Each characteristic can be decomposed into a set of attributes $A i$
Table 1.

Fundamental definitions for servitization decision reference model (Dahmani et al., 2016)

\section{eftributes $A$ i}

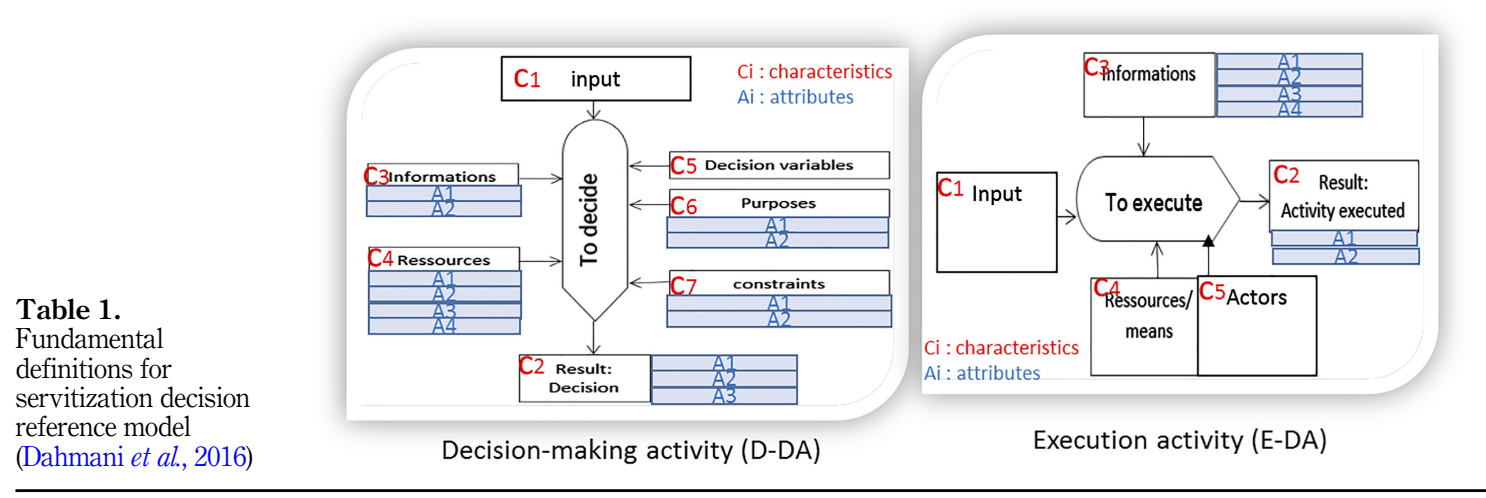

horizon (strategic, tactical 1 or tactical 2 or operational). It embeds a set of Decision-Making Activities; then (2) Decision Activity (DA) that represents a basic/elementary decision. Both this notions go into lower granularity levels in the model of MP (detailed definitions are in Table 1).

Based on these concepts, two key modeling components are proposed. The first component provides decision-makers with an overall vision of the whole servitization decision-making process: this is the servitization decision-making grid illustrated in Figure 3. Then, the second component is a more detailed process model, where each Critical Decision Process (CDP) can be further described into a so-called network.

As detailed in Dahmani et al. (2016), this modelling approach has been applied to build a full generic model covering the entire servitization decision-making process. The full model is composed of $3 \mathrm{MP}, 12 \mathrm{CDP}$ and $47 \mathrm{DA}$ (Figure 3 ). The genericity of the model makes possible its re-usability for different industrial contexts, while the detailed network of DA for each $\mathrm{CDP}$ can be adapted to the specific contextual factors. This generic model is called in the rest of the paper the "Reference Model" for servitization decision-making process. This Reference Model, adapted to any specific company, is the basis for later risk-oriented diagnosis.

\subsection{Coupling servitization decision-making process and risk management}

Risk analysis in servitization is treated in literature mainly through descriptive approaches and there is no analytical method able to help decision-makers understand how risks could be 
positioned in a servitization transition process. Literature focuses on defining external risks related to the environment of the company, more than the internal decision processes, as they are executed by the company's decision-makers. The challenge considered below is the need for an analytical method able to help steering servitization transition through risk analysis and management. We propose then in Figure 4 the overall conceptual framework to build our proposal. We specify also the specific scope of this research limited to the diagnosis part of the framework.

This conceptual framework considers that servitization risks are closely linked to the quality of the decision-making activities applied during the whole transition process. Improving the way to specify and deploy the decisional situations offers a pertinent path to improve the quality of the resulting servitization decisions, thus a path to reduce the risks of servitization failure.

Thus, at a methodological level (Figure 4), the first need is to make a structured analysis of decision-making activities and processes. The pragmatic goal of this analysis consists in identifying so-called "Risk factors" which can affect decision situations and, at the tool level, the approach is based on the use of formalized model of servitization decision process, specifically developed for this purpose.

The second methodological step consists in characterizing the whole set of decision situations and processes throughout the entire servitization process by indicators of risk occurrence and impacts. The output consists in diagnosing which decision activities or processes are submitted to high risks (so called "risky decision situation"). At the tool level, measures and indicators of risks occurrence and impacts are proposed and further discussed in the paper (cf. Section 4).

Then, the third methodological step consists in defining and implementing action plans for risk mitigation, with the objective to reduce so-called "Potential servitization failures". At the tool level the approach includes a procedure to build remediation plans. This third methodological level (risk mitigation) is beyond the scope of the paper, and planned for ulterior publications.

Based on this conceptual framework the following sections formalize a risk orienteddiagnosis for the servitization process.

\section{Risk characterization: potential occurrence of risks}

To assess the possibility of occurrence of a risky decision situation in servitization decision process, we propose to evaluate the occurrence of decision-making risks through two

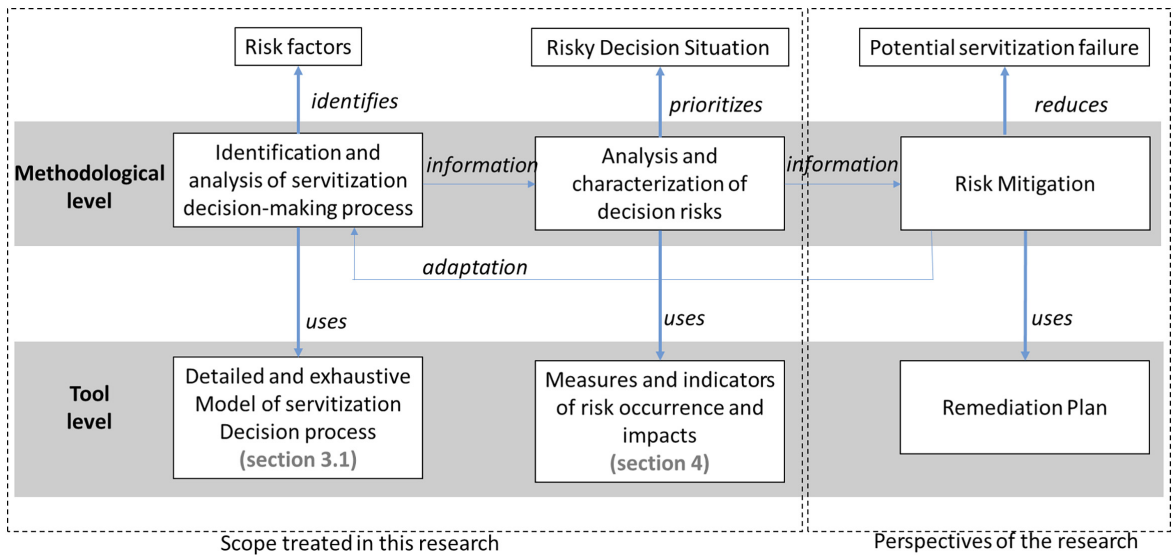

Figure 4. Conceptual framework for risk management along the servitization decision-making process 
perspectives. The first one relates to the degree of rationality of decision processes: this can be evaluated with objectivity, by measuring discrepancies between the effective way to take decisions and the Reference Model for servitization decision-making, introduced in Section 3.1. In the following sections, this first evaluation is formalized via the estimator of "Procedural Reliability." The second evaluation perspective represents a subjective point of view related to the confidence of decision-makers concerning the outputs of the decisions. This evaluation is implemented by the definition and assessment of an estimator of "Decision Confidence Level," according to decision-makers' opinions. We propose to evaluate the potential occurrence of risks via a simultaneous use of both indicators.

\subsection{Decision procedural reliability and decision confidence: conceptual positioning}

(1) Decision procedural reliability

Conceptually, the quality of a decision is partially related to the quality of information used to build it (Chengalur-Smith et al., 1999; Mouzhi and Helfert, 2007). Therefore, in the context of servitization, we consider the origins of decision risks mainly embedded in the approach used to take decisions, thus decision-making activities and processes. A decision made according to deficient or inadequate decision-making process carry potential failures, which can reinforce the occurrence of decision risks. We consider that the potential occurrence of decision risks is higher when the quality of the decision-making process implemented by a company is low. Then, comes the question, "How to be able to assess the quality of decisionmaking processes?"

At the same time, in a servitization transition context, the decision-maker's position is often influenced by a lack of useful internal and external information. Consequently, it is impossible to foresee all possible decision options and to evaluate the different utility levels to make an optimal choice (Savage, 1954). We opt for a positioning consistent with a servitization decision process: our purpose is to give more importance to the decision-making process than decision choices. Procedural rationality founded in 1979 by H. Simon (Vidaillet et al., 2005) is consistent with our purpose of analysis and diagnosis for servitization decisionmaking process. According to this approach, a decision is considered as a solution to a given problem; it is thus assessed on the reasoning adopted in the problem resolution.

We consider then the procedural reliability to assess the reliability of the decisions made in the servitization process.

(2) Decision confidence

A decision-making process is a human cognitive process influenced by intuition and the unconscious creativity of the decision-maker (Helfer et al., 2013). Any innovative change in an enterprise strategy involves an internal reflection related to the decision-maker's personal experience and beliefs; this is particularly true for SME. In the context of analysis and diagnosis for servitization process, analyzing the procedural rationality of decision-makers can characterize and evaluate the reliability of the decision, but this does not include the subjective judgment. Human judgment in decision choices is not necessarily consistent with the pre-established procedural rationality and depends on the complex cognitive processes of a decision-maker, his intuition and his convictions.

The decision-maker recognizes the limits of his capabilities, and can make decisions that are not necessarily logical or rational (Hodgkinson et al., 2009). In a complex decision-making context, the intuitive judgment represents an essential element of strategic competence. Furthermore, several studies of decision making in a variety of complex contexts have shown that rational analysis remains insufficient to deal with complexity. In some cases, intuition could even replace rational analysis (Woiceshyn, 2009). Dhami and Thomson (2012) propose a 
summary of the different currents of interpretation of the decision-making position that highlight the advantages of rational analytical decision compared to intuitive decisions and trends that put forward the contribution of intuitive thinking while keeping the benefits of rational decision. The conclusion states that effective managers should combine intuition and analysis to meet specific and complex decision problems. This shared perception of decision is mentioned in the literature through the concept of "quasirationality" (Hammond, 1996, 2000; Dhami and Thomson, 2012).

Inspired by this concept of quasi rationality, in the analyzing approach of risk occurrence in servitization, we consider that all DA included in the process are based on rational analysis that depends on the context in which it operates "procedural reliability," in parallel with the intuitive judgment developed for each decision-making choice measured through "decision confidence."

\subsection{Decision procedural reliability and decision confidence: assessment and estimators}

(1) Decision procedural reliability assessment

We propose to evaluate procedural reliability adopted by decision-makers according to the Reference Model that we have established. We consider this model as a reference guide to reflect a standard reference reliable rationality, which facilitates understanding of the process followed by decision-makers (Figure 5). This will be named "Procedural reliability of decision making process" $\left(R_{k}\right)$, and more specifically we define this procedural reliability according to:

An estimate of the proximity between (1) the reference servitization decision-making process modeled $a$ priori and (2) the effective decision-making process, followed by decisionmakers.

The procedural reliability will provide an estimation of this proximity. We propose to build the evaluation of this proximity between two processes according to the finest modeling process level: the Decision Activity (DA).

For the detailed explanation of the following measurement it's necessary to consult the third line of Table 1, to understand the details of modeling a DA.

$\mathrm{A} \mathrm{DA}_{k}$ of the "effective decision-making process" will be considered reliable when the characteristics $\left(C_{i}\right)$ and attributes $\left(A_{j}\right)$ of this activity are similar to those of the corresponding activity in the Reference Model for a decision-making process. In other words, it can be considered as a reliable $\mathrm{DA}_{k}$ only if the decision-maker has considered all the predefined elements in the Reference Model.

The decision-process reliability $R_{k}$ for $\mathrm{DA}_{k}$ is evaluated by aggregating the reliability coefficients among the $\mathrm{m}$ attributes $\left(A_{j}\right)$ of the $\mathrm{n}$ characteristics $\left(C_{i}\right)$, taking into account the index of the presence (ind $=1$ ) (resp. absence; ind $=0$ ) means that the decision-maker took (resp. did not take) the attribute into account in his decision-making process.

It is therefore necessary to capture and model the actual decision-making process, using the same formalism (networks of activities) as for the Reference Model.
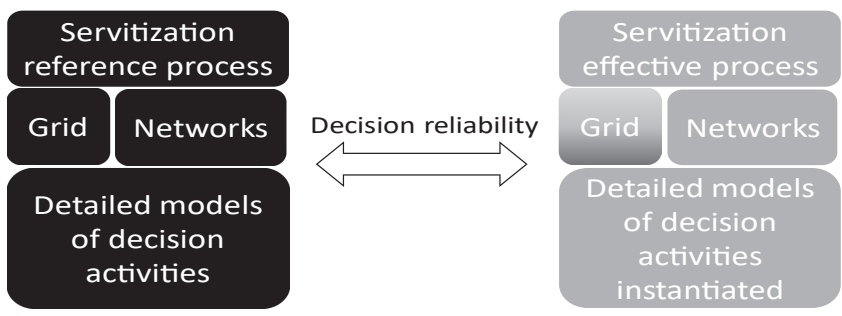

Figure.5.

Conceptual scheme for decision reliability assessment' 


$$
R_{k}=\sum_{i, j=1}^{n}\left(\operatorname{ind}_{i} \times \operatorname{coef}_{j}\right)
$$

$R_{k}=0$ if no decision attribute is present; situation of Ignored DA

$R_{k}=1$ if all decision reference attributes are present in the effective decision-making process; it refers to a situation when the decision-maker proceeds by following closely the reference model

Coeff: represents the coefficient for every attribute representing a part of decision characteristics

Example: for a DA-D "Develop internal value chain" (7 characteristics are considered) for reliability assessment, every characteristic is represented through a coefficient of $\frac{1}{7}$; one characteristic C2 "Detailed output" contains three attributes. We consider a coefficient of $\left(\frac{1}{7} \times \frac{1}{3}=\frac{1}{21}\right)$ to assess this attribute.

(2) Decision confidence assessment

We propose to evaluate decision-maker confidence $(T)$ based on one characteristic (cf. line 3 in Table 1) of the decision-making reference model: the "Detailed Output" that brings together all decision results (decision choices made) under different $(j)$ attributes $(A)$ for a given DA: $\left(T(A)_{j}\right)$.

Confidence estimator $\left(T_{k}\right)$ converts the confidence assigned by decision-makers to their choices according to an easily understandable approach for the decision-maker.

$T(A)_{A=1 \text { to } j}=$ Evaluated confidence at the level of each attribute of the "output" characteristic of the $\mathrm{DA}_{k}$.

$$
T_{k}=\operatorname{average}\left(T(A)_{A=1 \text { to } j} ; K\right)
$$

The assessment of confidence is made through a questionnaire that first checks if the decision-maker has addressed the concerned decision; then asks to assess his confidence in the decision choices according to a qualitative ordinal scale of four levels ranging from "not confident", "somewhat confident", "confident", to "very confident". The choice of this pair scale aims to encourage the decision-maker to express an oriented choice avoiding neutral assessments. We aim to offer a polarized assessment of a decision-maker's judgment. Then, to deduce an agreed assessment of confidence on overall results of the DA, we assign scale levels ranging from coefficients 0 to 1 , according to the growing expressed confidence level ([0] for "not confident"; [0.25] for "somewhat confident"; [0.5] for "confident"; [1] for "very confident").

Once confidence is assessed for every DA attribute of the output $T(A)_{j}$, we proceed to the aggregation of assessment through the average of the coefficients allocated among attributes $\left(T_{k}\right)$.

It should also be noted that our approach does not aim to explain the origins of the confidence of the decision-makers or the relevance of their choices, our role is limited to quantifying the judgment of satisfaction or faith expressed by the decision-makers in their choices.

Finally, after these two evaluations, every decision-making activity can be formalized as follows

$$
D A_{k}=\left\{(C i)_{i=1 \text { to } n} ; R_{k} ; T_{k}\right\}
$$

$C_{i}=$ Characteristics for DA 
$R_{k}=$ reliability estimator for $\mathrm{DA}_{k}$;

$T_{k}=$ confidence estimator for $\mathrm{DA}_{k}$.

(3) Decision procedural reliability and decision confidence: aggregation on the level of $\mathrm{CDP}$

According to the reference model we defined for servitization decision making process, two important analysis levels were created, one focused on DA, the second one representing an aggregated point of view of the decision process (combining one time horizon and one MP) represented through the critical decision process (CDP). The CDP plays an important role in the diagnosis, therefore we need to evaluate the reliability and confidence indicators at its level, which gives an aggregated granularity.

Based on the detailed estimation of reliability and confidence in the level of DA, we aggregate the estimation in the level of $\mathrm{CDP}$ by considering the minimum value (for confidence and reliability) among all Decision Activity existing in the CDP.

$R^{C D P_{i j}}=\operatorname{Min}_{i j}(R k)$ represents the aggregated decision reliability

$T^{C D P_{i j}}=\operatorname{Min}_{i j}(T k)$ represents the aggregated decision confidence

Finally, the CDP can be formalized as a set of Decision Activities, together with two aggregated indicators

$$
\mathrm{CDP}_{i j}=\left\{\left(D A_{K} ; R_{k} ; T_{k}\right) ; R^{\mathrm{CDP}} ; T^{\mathrm{CDP}}\right\}
$$

$i=1-3$

$j=1-4$

The different estimators were created to allow normalizing the assessment for decision reliability and confidence, to make it possible to compare values.

The aggregated assessment we propose in the level of CDP will enable us to establish an aggregated adjusted vision for risk diagnosis for the servitization process. The global view is important to address an objective judgment about the situation of the process at one specific moment. The aggregation by the minimum we have chosen will enable to highlight the areas carrying a high potential occurrence of risk. Interpretation of risk occurrence will be the subject of the next section.

\subsection{Risk occurrence: 3 levels of diagnosis}

We evaluate risk occurrence according to both estimators: decision reliability and decision confidence. We consider that risk occurrence is highly probable if both "decision procedural reliability" concerning the decision-making process is not optimal and "decision-maker's confidence" is low. The interpretation of the "potential occurrence" of decision risks is presented in Table 2. This potential of occurrence can be studied at different levels of granularity: for each "Decision Activity" (DA), aggregated for a single "Critical Decision process" (CDP), or even more aggregated at the level of a Macro-Process (MP) (see Table 3).

The matrix (Table 2) is created based on the principle of parity judgments. The measurement we propose for the potential occurrence of risks has been first discussed and validated with experts, then confronted with feasibility and pertinence validation through a real industrial case study Ecobel) detailed in (Dahmani, 2015). We consider mainly that a decision which is "totally unreliable" and decision-maker is "not confident" is carrying a "very high" potential occurrence of risk. Following the same logic we deduce four levels to interpret the potential occurrence of risk: Very high; high; average and low. The most critical CDP are those carrying very high and high potential occurrence of risk.

Based on the three granularity levels underlined (DA, CDP and MP), three complementary levels of diagnosis are proposed. We identify a first level to compare decision reliability to 
Table 2.

Matrix for the interpretation of "Potential risk occurrence"

\begin{tabular}{|c|c|c|c|c|}
\hline \multicolumn{1}{c|}{ Confidence } & Not confident & $\begin{array}{c}\text { somewhat } \\
\text { confident } \\
\text { Reliability }\end{array}$ & confident & Very confident \\
\hline $\begin{array}{c}\text { Totally } \\
\text { unreliable }\end{array}$ & Very High & Very High & High & Average \\
\hline $\begin{array}{c}\text { Partly } \\
\text { unreliable }\end{array}$ & Very High & High & High & Average \\
\hline $\begin{array}{c}\text { Moderately } \\
\text { reliable }\end{array}$ & High & High & Average & Low \\
\hline Reliable & Average & Average & Low & Low \\
\hline
\end{tabular}

Table 3.

Potential risk occurrence diagnosis for the Automelec servitization process

\begin{tabular}{|c|c|c|c|}
\hline & $\begin{array}{c}\text { MP1 } \\
\text { PSS technical design }\end{array}$ & $\begin{array}{c}\text { MP2 } \\
\text { PSS Business model } \\
\text { transformation }\end{array}$ & $\begin{array}{c}\text { MP3 } \\
\text { Organizational changes } \\
\text { required to support PSS } \\
\text { implementation }\end{array}$ \\
\hline H1. Strategic & $\begin{array}{l}\text { PS1. Define PSS value } \\
\text { creation drivers }\end{array}$ & $\begin{array}{l}\text { PS2. Define the value } \\
\text { proposition }\end{array}$ & $\begin{array}{c}\text { PS3. Define business } \\
\text { processes }\end{array}$ \\
\hline $\begin{array}{c}\mathrm{H} 2 . \\
\text { Tactical } 1\end{array}$ & $\begin{array}{l}\text { PT1. Delineate the PSS } \\
\text { structure }\end{array}$ & $\begin{array}{l}\text { PT2. Define the value } \\
\text { architecture }\end{array}$ & $\begin{array}{c}\text { PT3. Plan organizational } \\
\text { changes }\end{array}$ \\
\hline $\begin{array}{c}\text { H3. } \\
\text { Tactical } 2\end{array}$ & $\begin{array}{l}\text { PT4. Define the PSS } \\
\text { infrastructure }\end{array}$ & $\begin{array}{l}\text { PT5. Select the profit } \\
\text { equation }\end{array}$ & $\begin{array}{l}\text { PT6. Establish level of } \\
\text { activity }\end{array}$ \\
\hline $\begin{array}{c}\text { H4. } \\
\text { Operational }\end{array}$ & $\begin{array}{l}\text { P01. Plan production } \\
\text { and characterize } \\
\text { customer interface }\end{array}$ & $\begin{array}{l}\text { P02. Deploy the business } \\
\text { model }\end{array}$ & $\begin{array}{c}\text { P03. Establish an } \\
\text { organization of work }\end{array}$ \\
\hline
\end{tabular}

decision confidence, for each DA of the servitization process. Profile diagrams are built, as illustrated in Figure 6. This gives a high-level vision of the decision coherence between the procedural rationality of the decision-maker and his intuition. Only decisions with a high difference between $R_{k}$ and $T_{k}$ will be further analyzed.

The second level of analyses diagnoses the risks at the level of the CDP. Risks are related to a specific field and a specific time horizon, making it possible to discriminate priorities for later risk mitigation. Detailed risk factors can also be further analyzed for each CDP.

The third level of diagnosis is related to an intermediate level based on the decision grid (Figure 6). The diagnosis here will give an aggregated estimation of the potential risk occurrence on the level of the axes: for every MP, to detect the MP concentrating weaknesses, and on the temporal horizon to detect if the risks are related to the short-term decision process, medium or long term. The methods proceed by calculating and delivering to the decision-makers various aggregations of the potential of risk occurrence, as illustrated in Figure 6.

It is necessary to highlight that for all estimators used we do not aim for a true value in the assessment, but for a discriminating approach to identify "weak decisions." Qualitative scales 


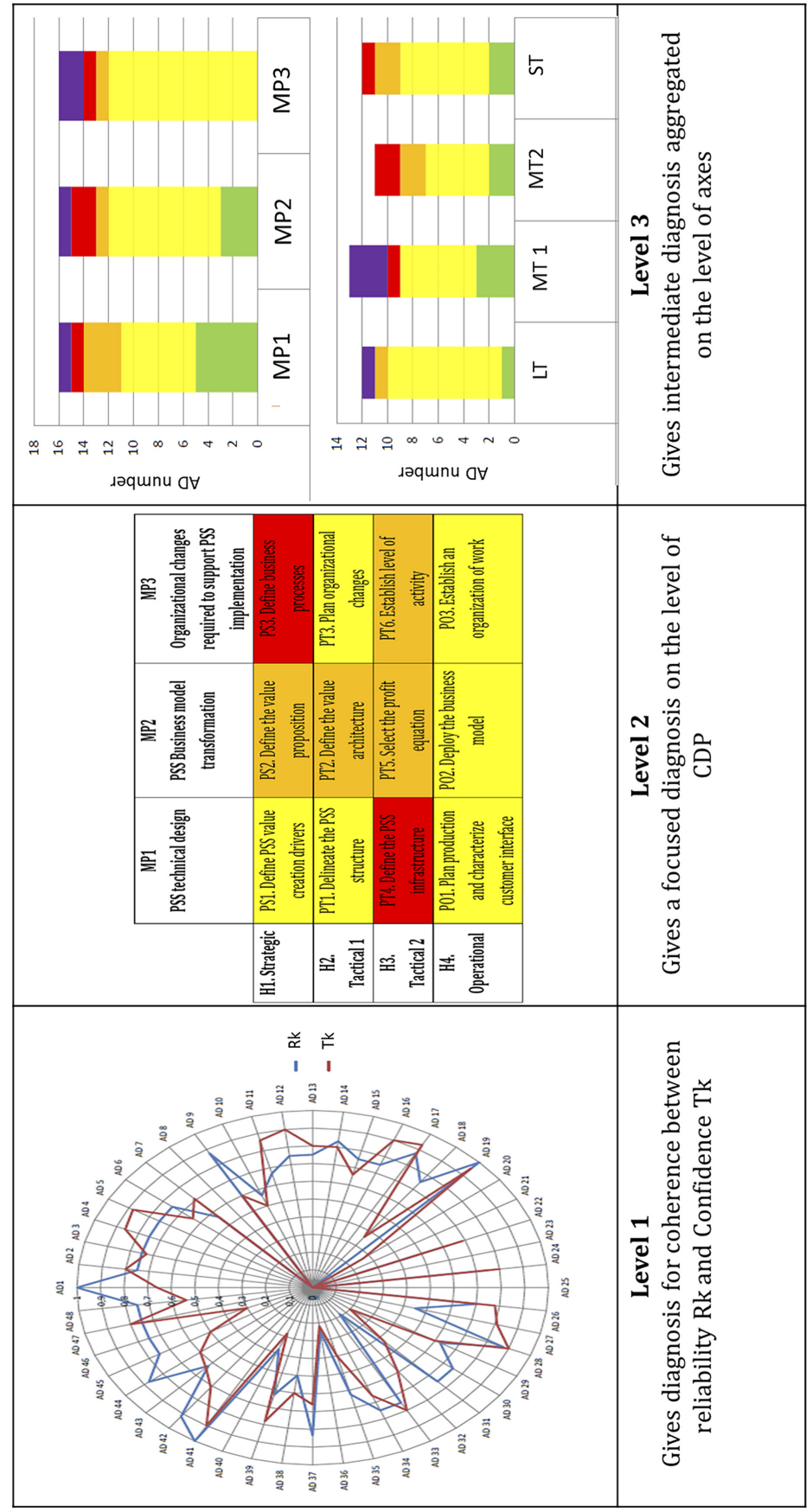

Figure 6. Servitization decision process diagnosis: Levels of interpretation 
allow finding decision confidence and reliability levels where they are more or less high, without looking for exact precision for the numerical values of these estimators. Only relative differences are actually useful. Therefore, limits of intervals for reliability and confidence are defined according to the studied case on which the method is applied.

\section{Case study: Automelec}

In this section we experiment the method defined on a real case study, to validate the feasibility of the method. We aim to instantiate the model and indicators we created to get a diagnosis result able to help decision-makers through the servitization transition process.

\subsection{Presentation of Automelec}

Automelec is a French SME located in the Rhône-Alpes Region. Automelec offers integrated automation systems (mechanical systems, industrial electricity, automation and IT) for the mining and extractive industry. In the 2010's, Automelec developed a new system called "Tamisoft," which consists of a particle size measuring line technology using 3D vision, applied to the extraction of gravel/stones. This system enables the early detection of possible drift compared to spot analyses on samples. It provides a report that certifies if the size of stones complies with the clients' standards, thus making the quality control more reliable.

Automelec planned to market Tamisoft as a PSS (Figure 7) and initiated a transition toward servitization. Tamisoft can be offered as a use-oriented PSS (the use of the system is sold but not the system itself) or as a result-oriented PSS (the result lies in the report that guarantees the size conformity of the stones) (Tukker, 2004). Automelec managers considered that the transition to a PSS delivery model was able to increase profitability and stabilize its operating cycles.

\subsection{Operational research methodology}

For case selection, we followed a straightforward, purposeful sampling approach (Patton, 2002). Our selection criteria identified information-rich cases that (1) focused on medium-sized companies, to allow a reliable representability of the method; (2) companies who have been initiating a strategic reflection around servitization transition since one year minimum; and (3) companies which are flexible to continuously redesigning their service offerings to provide customers with comprehensive solutions and long-term service agreements. This can refer also to companies with agile decision-making process, able to adapt to different changes.

Automelec satisfies these three criteria and was selected for the feasibility validation of the method. At the time of the research collaboration, Automelec's decision-making board

Figure 7.

Automelec transition to PSS through Oliva and Kallenberg (2003) servitization continuum

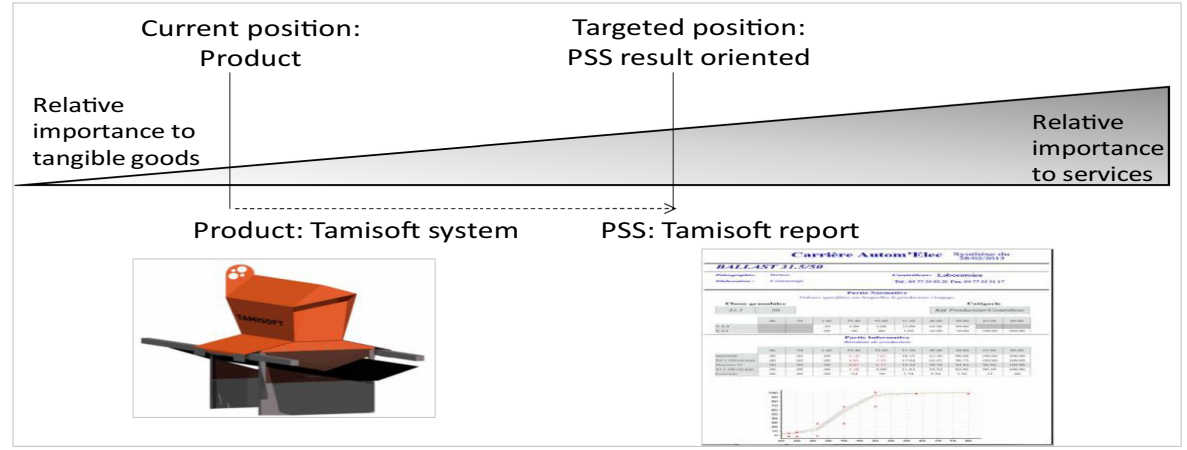


had launched the servitization transition project and confirmed the need to change the business model for the Tamisoft system.

Although Automelec shows high maturity in terms of strategic thinking and the need to establish a change in its business model, it encounters significant difficulties in defining the adequate trajectory required to fulfill the strategic objectives of servitization transition. The decision is highly centralized at the level of the leader, and the company does not have the means for strategic analysis or simulation that allow it to test and experiment different scenarios. Currently the company is trying to collect information from their customers; has initiated some limited experiments, but still needs assistance to get a clear vision of the possibilities and the significant criteria to consider in this transition.

The process faced by Automelec is representative of the situation analyzed by the method we propose, the difficulties developed by Automelec are related to the $3 \mathrm{MP}$ defined in the method, and the decision covers also strategic and operational perspectives.

For these reasons, we considered that Automelec would represent a valuable case to experiment and validate the method we propose. It would validate the resilience of the method in a different context than the Ecobel case study previously used for the first validation of the method (cf. Section 2).

We applied our diagnosis method to the Automelec case in three steps:

(1) Understanding of the strategic and organizational context: through three semidirected interviews of two hours each with the company's CEO. This step allowed establishing a representative model of the effective servitization decision-making process followed by the firm. This phase is based on an open questionnaire, for which we accompany the decision-makers to explain questions, and note responses. Then, we formalized the followed decision-making process according to the reference decision model;

(2) Assessment of the procedural reliability of decisions, and of the decision-maker's confidence in the taken decisions. To do so, we used the conceptual models developed for assessing estimators (cf. Section 4.2);

(3) Risk diagnosis. Risk estimators were calculated and analyzed to help highlight the weaknesses of the decision-making processes, before analyzing possible ways of improvement. The diagnosis procedure follows the 3 levels introduced before (cf. Section 4.3).

\subsection{Diagnosis results}

6.3.1 Level 1: general diagnosis - decision coherence. This diagnosis (Figure 8) is based on measuring and comparing the reliability $\left(R_{k}\right)$ and confidence $\left(T_{k}\right)$ for every DA of the process. This allows to build the profile of the decision process and to identify the DA carrying high incoherence (important difference between $R_{k}$ and $T_{k}$ ).

We note that for $67 \%$ of the process (32 DA), there is decisional coherence in the perception of the risks inherent to these DA where $R_{k} \sim=T_{k}$ : From an objective and subjective point of view, $38 \%$ of the process performed by Automelec $(18 \mathrm{DA})$ carries high decision-making risks, while $29 \%$ of the process (14 DA) carries low decision-making risks. For these $32 \mathrm{DAs}$, we consider that the decision-maker is aware of the potential decision risks. The systematic diagnosis completed via the modeling of decision-making situations and identification of risk factors (more details in Dahmani et al., 2016) makes it possible to confirm objectively some weaknesses already intuitively identified by the company, and further analyses the causal factors of these weaknesses.

On the other hand, $33 \%$ of the process (16 DA) expresses a decisional incoherence, where $R_{k}$ and $T_{k}$ do not follow the same trend. For $23 \%$ of the process (11 DA), the so-called objective 
Figure 8.

General diagnosis decision coherence for Automelec

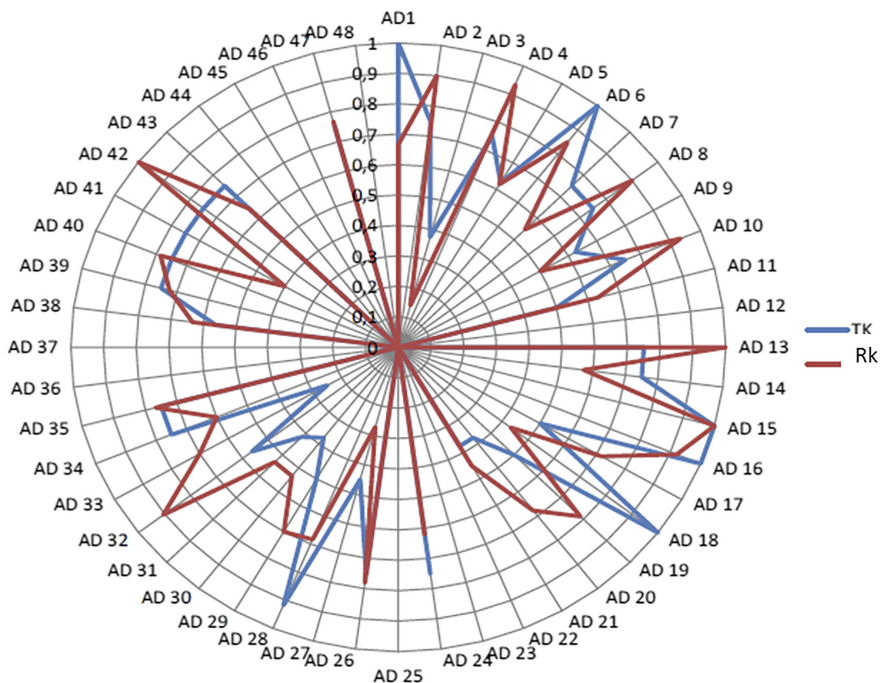

\begin{tabular}{|c|c|c|}
\hline Confidence & $\begin{array}{c}\text { T }_{\text {k. }} \text { Low } 23 \text { AD (48\%) } \\
T_{k} \in[0 ; 0,5]\end{array}$ & $\begin{array}{c}\mathrm{T}_{\mathrm{k}} \text {, High } 25 \mathrm{AD}(52 \%) \\
\mathrm{T}_{\mathrm{k}} \in[0,6 ; 1]\end{array}$ \\
\hline $\begin{array}{c}F_{k} \text { High } 29 \text { AD (61\%) } \\
F_{k} \in[0 ; 0,6]\end{array}$ & $\begin{array}{c}\text { Cohérence : } \mathrm{F}_{\mathrm{k}} \sim=\mathrm{T}_{\mathrm{k}} \\
18 \mathrm{AD}(38 \%)\end{array}$ & $\begin{array}{c}\text { Incohérence: } \mathrm{F}_{\mathrm{k}}<\mathrm{T}_{\mathrm{k}} \\
11 \mathrm{AD}(23 \%)\end{array}$ \\
\hline $\begin{array}{cc}\mathbf{F}_{\mathrm{k}} \text { Low } & 19 \mathrm{AD}(39 \%) \\
\mathrm{F}_{\mathrm{k}} \in[0,7 ; 1]\end{array}$ & $\begin{array}{c}\text { Incohérence: } \mathrm{F}_{\mathrm{k}}>\mathrm{T}_{\mathrm{k}} \\
5 \mathrm{AD}(10 \%)\end{array}$ & $\begin{array}{c}\text { Cohérence : } F_{k} \sim=T_{k} \\
14 \operatorname{AD~}(29 \%)\end{array}$ \\
\hline
\end{tabular}

risk is considered to be high compared to the subjective risk, considered to be low. This situation reflects an underestimation of the weakness of these concerned DAs, which can lead to the occurrence of "Unforeseen" decision-making failures

For $10 \%$ (5 DA) of the process, the DAs carry a subjective risk considered as high compared to the objective risk which is low. This puts forth a situation of incoherence, where the DA follow correctly the decision-making procedure defined in the Reference Model, but where the decision-maker remains uncertain of the resulting decision choices.

The detailed interpretation of these situations of incoherence can only be made by the decision-makers themselves, with the objective being to change their awareness of some of the key issues. A reminder that the final objective of this first level of diagnosis is to give an instant image of the decision-making process accomplished by the company. This represents a first descriptive synthesis, serving as a basis for later comparison. We plan to carry out this same diagnosis periodically during the servitization project (every 6 months, for example), in order to see progress in terms of reliability and confidence estimators, as well as in terms of decision-making coherence.

6.3.2 Level 2: specific diagnosis focused on CDP. This level of diagnosis focuses on the CDP; the objective is to measure an aggregation of the potential occurrence of decisional risk on every CDP of the model (Figure 3 ) through a code color developed in Table 2 . The evaluation is based on the different estimator tools we introduced in Section $4: R^{C D P_{i j}}$ and $T^{C D P_{i j}}$. The risk interpretation is based on Table 2.

This level of diagnosis for Automelec shows that the major risks are concentrated on strategic decisions related to the planning of organizational changes (PS3), and on tactical decisions about defining the PSS infrastructure (PT4). Indeed, Automelec is not able at this moment to define precisely the organizational changes require for implementation. At this 
stage of the project, the company is not aware that the business processes need to be redefined because of the new service-oriented activities (for instance the system maintenance or the monitoring of customer needs).

Regarding the PSS infrastructure definition, Automelec weakly defines the fundamental elements of the infrastructure necessary to ensure the delivery of the promised value. This concerns the minimum existing infrastructure necessary to monitor the functioning of the system. For the Tamisoft system one example of infrastructure would be to provide a stable access to Internet connection to ensure customer data transfer and analysis.

Decision processes related to organizational structure changes appears to be the most neglected ones. In fact, we observed that decision-makers of Automelec and for SMEs in general do not question the importance of professional changes imposed by servitization, they trust the reactivity and adaptation capacities of their companies. This may be true for a product-oriented PSS offer, where services represent support for an existing product, but for a use or result-oriented PSS offer such organizational changes become critical. Indeed, useoriented and results-oriented PSS imply a change in the core business of the company, which requires questioning collective skills and capabilities. In most of the cases, this change requires the involvement of new external actors in the company's value chain, and establishing formal partnerships with these stakeholders. In the case of Automelec the diagnosis acted as an alarm to increase their awareness.

The CDP PT6, related to defining an activity level for the servitized company also carries a high risk; this is about anticipating at least a reference minimum level of demand to organize the activity and check if available resources are sufficient.

Diagnosis allowed to notice that decisions related to technical design issues (MP1) are the most controlled ones (few DAs are ignored at this level), followed by decision processes responsible for setting up the business-model.

6.3.3 Level 3: intermediate diagnosis based on macro processes (MP) and decision horizons. For Automelec, the three MPs (MP1: Technical Design; MP2: Business model transformation; and MP3: Organizational changes) are marked by DAs carrying risks with relatively high potential of occurrence. We also note the presence of DAs fully ignored at the level of the three MPs, but most of ignored DAs are concentrated at the MP3. Thus, it can by hypothesized that for Automelec, MP3 has to be considered as a priority in the transition project.

These results could reflect a lack of global awareness of the business decision-maker regarding the importance of planning an organizational change process (MP3) and of designing the offer and the business model (MP2). However, this can also be explained by the intermediary positioning of Automelec in the transition process. This is a decision-making axis which has not yet been fully addressed by the company. Feedbacks from the manager show that planning organizational change is not a priority for Automelec because the decision-maker considers that the company has the expertise and experience necessary to ensure internal change: consequently, these DAs have been deliberately ignored. However, for questions related to external changes in terms of collaboration and partnership needs, some DAs were involuntarily ignored and require higher consideration.

For the other two MPs, only two DAs were ignored by the decision-maker. This shows a high overall awareness of the various issues related to the PSS design and business model. However, we find that several DAs belonging to MP2 (6 DAs) are marked by a relatively high potential occurrence of risk, versus only one DA for MP1. We can then hypothesize that, after $\mathrm{MP}$, the second priority for risk mitigation is MP2.

We also evaluated the distribution of the DAs of the decision-making process according to four decision-making horizons. Most of the ignored DA are concentrated in the short term and medium term 1 . We can thus hypothesize to consider the short-term decision-making horizon as a first priority for risk mitigation. This axis considers all of the operational decisions necessary to implement correctly the servitization strategy. This higher risk can be explained 
by the positioning of Automelec in the transition process: the decision-maker considers that the company is able to be reactive and calibrate its operation system in adaptation with possible changes from market demand: this consideration led to purposely ignore several DAs. The company claims to have the capacity and expertise to perform them, as soon as the process is well-advanced.

The second apparent priority axis is the medium term 1 , which concentrates the second highest number of ignored DAs (3 DAs). This axis embeds decisions aimed at planning medium-term resources, required to respond to strategic positioning. It is the intermediary between strategic and operational decisions.

The third priority axis is then included in the medium term horizon 2 , because it concentrates the highest number of DAs with relatively high potential risk occurrence (5 DAs), compared to the strategic horizon which seems to be the least affected.

6.3.4 Implications of the diagnosis for Automelec. Delivering this diagnosis for Automelec was very useful for the decision-makers. One first insight is related to the method and its ability to give different points of view of the performance of the decision process to accomplish the servitization transition. It helped the company to get a systemic view of the decision process, which contributes significantly to increase the awareness about the different weaknesses in the process. The three levels of diagnosis also helped to clarify the situation at distinct granularity levels, and to assess objectively the situation of the company leading to some discrepancies between intuitive and measurable situations. Through the systematic use of a reference model the approach increases the awareness of decisionmakers of a correct organization of decision-making activities. At a detailed level the reference models can be used to identify precise risk factors.

The second insight is about alerting and increasing awareness about the areas carrying a very high potential risk occurrence. The diagnosis helped to highlight parts of the process (MP3: organizational changes and medium term decisions) which were not identified as carrying high risks beforehand. This helped deducing course of actions: the diagnosis enabled Automelec leaders to rethink the importance of the infrastructure for the delivery of the system and some important contracting points (legal issues) were identified to be improved. The company highlighted some other added-values notably concerning (1) defining the level of activity of the company, (2) how to differentiate costs and activities related to the transition project and operational costs of the run or the business as usual after delivering the servitized system. Based on this other questions appeared about managing the follow up of the PSS, rewarding loyalty for users.

This experiment on the Automelec case has validated the feasibility of the method. Many contributions were identified by the decision board when discussing the diagnosis results. It helped to highlight the DA needing revision or deeper analysis. We can confirm the adaptability of the method and its ability to help understanding the servitization system. A first level of genericity of the method has been validated: it is not dependent on the sector of activity or the size of the company. We can notice that the approach can be particularly useful for SMEs (when applied by an expert) because it provides objective results, contributing to a better knowledge of the servitization mechanisms by the managers and increases their degree of confidence in how they manage a transition project.

Some limitations arise, related to its temporal representation of the process. The fact that the application of the approach requires an intermediary actor in charge of the diagnosis with a high understanding of servitization concepts and specificities and with the capacity to interpret consistently the measurements provided can also represent a limitation.

\subsection{Feedback from experience, theoretical contributions and managerial implications}

Through this research we propose a new approach for using risk diagnosis methods in order to help the piloting of the servitization decision-making process. The interpretation resulting 
from risk analysis helps decision-makers to identify areas of weakness in their decision processes. This diagnosis process can be included at different milestones of servitization projects. Decision-makers could take advantage of the approach as a continuous learning approach to enhance their decision-making capacities on servitization. Some discussion key points are emphasized below:

First discussion concerns the utility of the methodological framework that we propose, which is related to the utility brought by its results. This utility is co-constructed and codeveloped with the company's decision-makers. We observed during the study a first utility of the methodological framework stemming from the decision diagnosis. Controlling risks starts by increasing awareness of their existence. The deployment of the methodological framework that we propose then allows decision-makers to become aware of the various decision risk factors included in the decision-making process that they are carrying out. This increases the visibility of decision-makers and help them to focus on the most critical issues. This benefit consists in shifting the leader's point of view to face complex decisions of servitization strategy. The manager dilemma is no longer to answer the direct question of "what is the right strategy to steer servitization transition," but rather indirectly to answer "how can I deploy the internal decision-making capacity to meet servitization's most important objectives." The sought utility is therefore a long-term impact on the decisionmaking capacity of the company.

A complementary utility is linked to the discussion of potential remediation approaches. The diagnosis results contributed significantly to enhance the awareness of decision-makers for a better control of the transition process. The diagnosis ensures a better performance in terms of understanding the decision-making context and the impacts of decision-making choices which contribute to the overall success of servitization transition.

To support such a diagnosis, a conceptual benefit of the research is related to risk occurrence assessment defined according to the confidence and the reliability based on a reference model to identify the level of control for the decision process: individually, and according to decision critical processes and aggregated according to axes. These different aggregations provide complementary points of view that will help decision-makers to position the adequate servitization trajectory.

Another interest of the study is related to the evaluation estimators that we defined: "Procedural reliability," "Decision-making confidence" and estimator of "Potential risk occurrence." These qualitative estimators are managed by quantitative tools in order to ensure the genericity of the model, but their interpretation is qualitative and makes it possible to explain complex systems. In a more global vision, we consider the usefulness of this proposal of the methodological framework to help decision-makers to explicit their strategic thoughts. This concerns as much big companies as SMEs. The approach allows managers to explain their strategy or what they consider to be a strategy: therefore it makes it possible to differentiate between what relates to strategic objectives and what relates to the strategy itself or the path to deploy the strategy and achieve the objectives.

Another discussion is related to the time and servitization process maturity when the diagnosis could be applied. In the adopted approach, our positioning was focused on the analysis of the before-planning phase or initiating phase for servitization project of an industrial company. We recommend providing decision support even during the planning and executing, to alert corporate decision-makers to possible failures in their decision-making processes. As a result, the proposed diagnosis approach is part of a vision of vigilance and precaution, rather than a curative one. This approach is able to enhance the maturity of decision-making process for companies, and improves their overall organizational agility during strategic transitions.

In the area of risk management, a clear contribution of this work lies in the proposal of a contextualization approach of risk diagnosis according to the specific framework of 
servitization decision-making process. This approach makes it possible to perceive decisional risks in a global way: through their origins included in the servitization decision-making process and their impacts that threaten the strategic objectives of value creation.

Then, through the case study, we also observed managerial implications of the method related to its ability to help decision-makers structure and explicit their strategy. The framework allows an overview of the servitization process of the company in general. Other managerial implications are related to the diagnosis results produced by the method helping decision-makers to reduce uncertainty and develop decision-making capabilities for the servitization process.

The scope of this paper is limited to a part of the conceptual and methodological framework introduced in Figure 4. This full conceptual framework includes the construction of a remediation plan aimed at deploying risk mitigation actions. The whole approach thus brings not only conceptual benefits (based on risk management for servitization) but also operational benefits by a structured method leading to operational and applicable action plans. This responds also to the challenges of operationality identified in the initial positioning.

Nevertheless, the research question is not closed: many perspectives could improve the method and overall, its adaptability and efficiency should be assessed on a larger panel of case studies.

\section{Conclusions and perspectives}

Industrial enterprise transition from product selling towards an integrated offer of PSS induces dynamic systemic changes for the company. This transition impacts all components related to the offer, the core business, the value construction and sharing between the company and its subscribers as well as its internal organization. In this research we propose a different approach to consider risks in steering innovative servitization process. We propose a proactive approach that aims to support decision-makers in the trajectory of the servitization of their company. In our vision, the risk diagnosis can help to raise awareness of the weaknesses of the process and then reorient the decision-making trajectory of the company. The impact upon society of this research focuses on its ability to facilitate complex decision-making for strategic transition process for organizations and particularly SMEs. Due to their limited resources, most SMEs have difficulties to conduct complete strategic planning for strategical transformations of their business. They lack control over the highlevel vision. We believe that helping SMEs to gain control and autonomy over their business, especially in a transformation context, will bring positive impacts to the local industrial fabrics, local economical networks and societal conditions of the workers. It increases the climate of stability and confidence for the local business environment.

The approach we propose in this work through the different phases helps decision-makers better understanding the possible opportunities for their business development and growth. The diagnosis allows them to get an overview about the performance of their decisionmaking process through risk diagnosis. It helps limiting uncertainty and ensuring a better awareness of the different decisional risks in order to optimize mitigation actions.

One of the limits of this work is the concentration on the firm's internal decision-making environment. The model is based broadly on the vision expressed by the company's decisionmakers. We recognize this limitation, and we consider the perspective of highlighting the influence of external factors on decision-making in future works. This would then require a deepening and a classification of the different contextual and environmental factors that can influence servitization strategy for the industrial enterprise.

In addition, we consider at the end of this work a last perspective in the deployment of the methodological framework. We did not consider some variables that may impact the decision-making process significantly, such as the risk impacts or severity; the cost generated 
by questioning decisions made carrying high risks; or the risk appetence or risk aversion of decision-makers. One of the perspectives of this study concerns the possibility of taking into account these factors, thus increasing the utility of the decision-making results provided, customizing them specifically to the company situation and vulnerability characteristics.

\section{References}

Alonso-Rasgado, M.T., Thompson, G. and Dannemark, O.J. (2004), "State of the art in service design and modeling", VIVACE Consortium Members, (Report).

Baines, T.S., Lightfoot, H.W., Evans, S., Neely, A., Greenough, R., Peppard, J., Wilson, H. (2007), "Stateof-the-art in product-service systems", Proceedings of the Institution of Mechanical Engineers, Part B: Journal of Engineering Manufacture, Vol. 221 No. 10, pp. 1543-1552, doi: 10.1243/ 09544054JEM858.

Baines, T., Lightfoot, H., Benedettini, O. and Kay, J.M. (2009), "The servitization of manufacturing: a review of literature and reflection on future challenges", Journal of Manufacturing Technology Management, Vol. 20 No. 5, pp. 547-567.

Barbier, J.M. (dir.) (1996), Savoirs théoriques et savoirs d'action, Presses universitaires de France, Paris.

Behrendt, S., Jasch, C., Kortman, J., Hrauda, G., Pfitzner, R. and Velte, D. (2003), “« Eco-service development-reinventing supply and demand in the European union »", Management of Environmental Quality: An International Journal, Vol. 14 No. 3, pp. 424-25.

Benedettini, O., Neely, A. and Swink, M. (2013), "Service types and their differential risk effects for manufacturing firms: an empirical analysis", Spring Servitization Conference, Aston Business School, May 20-21.

Bird, B. (2015), "Implementing entrepreneurial ideas: the case for intention”, Academy of Management Review, Vol. 13 No. 3, pp. 442-453, doi: 10.5465/AMR.1988.4306970.

Boucher, X. and Medini, K. (2016), "Towards a generic meta-model for PSS scenarios modelling and analysis", Procedia CIRP, Elsevier, Vol. 47, pp. 234-239, doi: 10.1016/J.PROCIR.2016.03.038.

Boughnim, N. and Yannou, B. (2005), "Using blueprinting method for developing product-service systems", International Conference of Engineering Design (ICED), Melbourne, August 15-18.

Burton, J., Story, V., Zolkiewski, J., Raddats, C., Baines, T.S. and Medway, D. (2016), "Identifying tensions in the servitized value chain", Research-Technology Management, Vol. 59 No. 5, pp. 38-47, doi: 10.1080/08956308.2016.1208042.

Bustinza, O.F., Bigdeli, A.Z., Baines, T. and Elliot, C. (2015), "Servitization and competitive advantage: the importance of organizational structure and value chain position", Research-Technology Management, Industrial Research Institute, Vol. 58 No. 5, pp. 53-60, doi: 10.5437/ $08956308 X 5805354$.

Chen, D., Doumeingts, G. and Vernadat, F. (2008), "Architectures for enterprise integration and interoperability: past, present and future", Computers in Industry, Vol. 59 No. 7, pp. 647-659.

Coba, K.M., Boucher, X., Medini, K. and Gonzalez-Feliu, J. (2019), "Simulation-based approach to apply uncertainty evaluation framework, for PSS economic models 11th CIRP Conference on Industrial Product-Service Systems”, IPS, Vol. 2, doi: 10.1016/j.procir.2019.02.138.

Cook, M.B., Bhamra, T.A. and Lemon, M. (2006), "« The transfer and application of Product Service Systems: from academia to UK manufacturing firms »", Journal of Cleaner Production, Vol. 14 No. 17, pp. 1455-65, doi: 10.1016/j.jclepro.2006.01.018.

Chengalur-Smith, InduShobha, N., Ballou, D.P. and Pazer, L.H. (1999), "« the impact of data quality information on decision making: an exploratory analysis ». Knowledge and Data Engineering", IEEE Transactions on, Vol. 11 No. 6, pp. 853-64.

Classen, M. and Friedli, T. (2019), "Value-Based Marketing and Sales of Industrial Services a systematic literature review in the age of digital technologies", 11th CIRP Conference on Industrial Product-Service Systems, IPS2 2019, May 2019, Zhuhai-Hong Kong, China. 
Crowley, E., Burton, J. and Zolkiewski, J. (2018), "Servitization intent as a factor in the servitization process", Journal of Business and Industrial Marketing, Emerald Publishing Limited, Vol. 33 No. 8, pp. 1125-1140, doi: 10.1108/JBIM-08-2016-0199.

Dahmani, S. (2015), Proposition D'un Cadre Méthodologique Pour La Gestion Du Processus De Servicisation En Entreprise Industrielle: Approche Basée Sur Les Risques Décisionnels, $\mathrm{PhD}$ thesis, Ecole des mines de Saint-Etienne, Saint-Etienne, available at: https://tel.archivesouvertes.fr/tel-01258186.

Dahmani, S., Boucher, X., Peillon, S. and Besombes, B. (2016), "A reliability diagnosis to support servitization decision-making process", Journal of Manufacturing Technology Management, Emerald Group Publishing Limited, Vol. 27 No. 4, pp. 502-534, doi: 10.1108/JMTM-06-2015-0044.

Dahmani, S., Boucher, X. and Peillon, S. (2016) Industrial Transition through Product-Service Systems: Proposal of a Decision-Process Modeling Framework, Springer, Berlin, Heidelberg, pp. 31-39, doi: 10.1007/978-3-642-40543-3_4.

David, A. (2003), “«Etude de cas et généralisation scientifique »", Sciences de Gestion, No 39, pp. 139-66.

Dhami, M.K. and Thomson, E. (2012), "« On the relevance of Cognitive Continuum Theory and quasirationality for understanding management judgment and decision making »", European Management Journal, Vol. 30 No. 4, pp. 316-26, doi: 10.1016/j.emj.2012.02.002.

Doualle, B., Medini, K., Boucher, X., Brissaud, D. and Laforest, V. (2020), "Selection method of sustainable product-service system scenarios to support decision-making during early design stages", International Journal of Sustainable Engineering, Vol. 13 No. 1, pp. 1-16, doi: 10.1080/ 19397038.2019.1660432.

Doumeingts, G., Chen, D. and Marcotte, F. (1992), "Concepts, models and methods for the design of production management systems", Computers in Industry, Vol. 19 No. 1, pp. 89-111.

Doumeingts, G., Ducq, Y., Vallespir, B. and Kleinhans, S. (2000), "Production management and enterprise modelling", Computers in Industry, Vol. 42 Nos 2-3, pp. 245-263.

Eisenhardt, K.M. and Graebner, M.E. (2007), "Theory building from cases: Opportunities and challenges", Academy of Management Journal, Vol. 50 No. 1, pp. 25-32, doi: 10.5465/AMJ.2007. 24160888.

Gebauer, H. and Friedli, T. (2005), "Behavioral implications of the transition process from products to service", Journal of Business and Industrial Marketing, Vol. 20 No. 2, pp. 70-78.

Gebauer, H. and Kowalkowski, C. (2012), "Customer-focused and service-focused orientation in organizational structures", Journal of Business and Industrial Marketing, Vol. 27 No. 7, pp. 527-537.

Gebauer, H., Fischer, T. and Fleisch, E. (2010), "Exploring the interrelationship among patterns of service strategy changes and organizational design elements", Journal of Service Management, Vol. 21 No. 1, pp. 103-129.

Gombault, A. (2005), Chapitre 9. Méthodes de développement d'échelles pour questionnaires d'enquête, in De Boeck Supérieur, (ed.), Méthodes \& Recherches, De Boeck Supérieur, available at: http:// www.cairn.info/resume.php?ID_ARTICLE=DBU_ROUSS_2005_01_0245.

Gourc, D. (2006), Vers un modèle général du risque pour le pilotage et la conduite des activités de biens et de services: Propositions pour une conduite des projets et une gestion des risques intégrées, Habilitation à Diriger des Recherches, Institut National Polytechnique de Toulouse-INPT, Toulouse.

Hammond, K.R. (1996), Human Judgement and Social Policy: Irreducible Uncertainty, Inevitable Error, Unavoidable Injustice, Oxford University Press, available at: https://books.google.fr/books? $\mathrm{hl}=$ fr\&lr=\&id=VxRnDAAAQBAJ\&oi=fnd\&pg=PR9\&dq=Human+Judgement + and + Social + Policy:+Irreducible+Uncertainty,+Inevitable+Error\&ots $=$ xvRICFFrbE\&sig=y3SxS-Vc_TupArT 6FC_v-mYW_-U\&redir_esc $=y \# v=$ onepage\&q=Human Judgement and Social Policy $\% 3 \mathrm{~A}$ Irreducible Uncertainty \% $2 \mathrm{C}$ Inevitable Error\&f=false. 
Hammond, K.R. (2000), Judgments under Stress, Oxford University Press, Oxford, available at: https:// books.google.fr/books?hl=fr\&lr $=\& \mathrm{id}=7 \mathrm{FoMMPO} 11 \mathrm{AC} \&$ oi=fnd\&pg $=\mathrm{PP} 2 \& \mathrm{dq}=$ Judgments + under+Stress\&ots=FHOzh_iFeX\&sig=ZLRTeTlAYfJpPazapbsPlxSOCO0\&redir_esc $=\mathrm{y} \# \mathrm{v}=$ one page\& $\mathrm{q}=$ Judgments under Stress\& $\mathrm{f}=$ false.

Helfer, J.P., Kalika, M. and Orsoni, J. (2013), Management Strategique, 10th ed., Vuibert, available at: www.tcpdf.org (accessed 28 June 2019).

Hodgkinson, G.P., Sadler-Smith, E., Burke, L.A., Claxton, G. and Sparrow, R. (2009), “" intuition in organizations: implications for strategic management »”, Long Range Planning, Vol. 42 No. 3, pp. 277-97, doi: 10.1016/j.lrp.2009.05.003.

Hou, J. and Neely, A. (2013), "Barriers of servitization: results of a systematic literature review", Spring Servitization Conference, Aston Business School, May 20-21.

Johansson, P. and Olhager, J. (2006), "Linking product-process matrices for manufacturing and industrial service operations", International Journal of Production Economics, Vol. 104 No. 2, pp. 615-624.

Kowalkowski, C., Persson Ridell, O., Röndell, J.G. and Sörhammar, D. (2012), "The co-creative practice of forming a value proposition", Journal of Marketing Management, Vol. 28 Nos 13-14, pp. 1553-1570, doi: 10.1080/0267257X.2012.736875.

Kowalkowski, C., Windahl, C., Kindström, D. and Gebauer, H. (2015), "What service transition? Rethinking established assumptions about manufacturers' service-led growth strategies", Industrial Marketing Management, Vol. 45, pp. 59-69.

Lewin, K. (1951), In Cartwright, D. (Ed.), Field Theory in Social Science: Selected Theoretical Papers, Harpers, Oxford.

Lightfoot, H., Baines, T. and Smart, P. (2013), "The servitization of manufacturing: a systematic literature review of interdependent trends", International Journal of Operations and Production Management, pp. 1408-1434, doi: 10.1108/IJOPM-07-2010-0196.

Lenka, S., Parida, V., Sjödin, D.R. and Wincent, J. (2018), "Towards a multi-level servitization framework: conceptualizing ambivalence in manufacturing firms", International Journal of Operations and Production Management, Emerald Group Publishing, Vol. 38 No. 3, pp. 810-827, doi: 10.1108/IJOPM-09-2016-0542.

Meïr, H., Völker, O. and Funke, B. (2011), "Industrial product-service systems (IPS2) - paradigm shift by mutually determined products and services", International Journal of Advanced Manufacturing Technology, Vol. 52 Nos 9-12, pp. 1175-1191.

Mont, O. (2004), Product-service Systems: Panacea or Myth?, Doctoral Dissertation, International Institute for Industrial Environmental Economics, Lund University, Lund.

Mouzhi, G. and et Helfert, M. (2007), “« A review of information quality research-develop a research agenda »", Paper presented at the International Conference on Information Quality 2007. Citeseer.

Murillo-Coba, C., Boucher, X., Medini, M. and Gonzalez Feliu, J. (2019), "Simulation-based approach to apply uncertainty evaluation framework for PSS economic models, 11th CIRP Conference on Industrial Product-Service Systems, IPS2 2019”, May 2019, Zhuhai-Hong Kong, China.

Neely, A. (2007), The Servitization of Manufacturing: An Analysis of Global Trend, 14th European Operations Management Association, Ankara, June 17-20.

Nudurupati, S.S., Lascelles, D., Wright, G. and Yip, N. (2016), "Eight challenges of servitisation for the configuration, measurement and management of organisations", Journal of Service Theory and Practice, Emerald Group Publishing Limited, Vol. 26 No. 6, pp. 745-763, doi: 10.1108/JSTP-022015-0045.

Oliva, R. and Kallenberg, R. (2003), "Managing the transition from products to services", International Journal of Service Industry Management, Vol. 14 No. 2, pp. 160-172.

Oluwafemi, I. and Laseinde, T. (2020), "Empirical assessment of cyber-physical systems influence on industrial service sector: the manufacturing industry as a case study", Advances in Intelligent Systems and Computing, Springer, Vol. 1026, pp. 1058-1065, doi: 10.1007/978-3-030-27928-8_157. 
Patton, M.Q. (2002), "Two decades of developments in qualitative inquiry", Qualitative Social Work: Research and Practice, Vol. 1 No. 3, pp. 261-283, doi: 10.1177/1473325002001003636.

Peillon, S., Pellegrin, C. and Burlat, P. (2015), "Exploring the servitization path: a conceptual framework and a case study from the capital goods industry", Production Planning and Control, Vol. 26 Nos 14-15, pp. 1264-1277.

Rabetino, R., Kohtamäki, M. and Gebauer, H. (2017), "Strategy map of servitization", International Journal of Production Economics, Elsevier, Vol. 192, pp. 144-156, doi: 10.1016/J.IJPE.2016.11.004.

Raddats, C., Kowalkowski, C., Benedettini, O., Burton, J. and Gebauer, H. (2019), "Servitization: a contemporary thematic review of four major research streams", Industrial Marketing Management, Elsevier, pp. 207-223, doi: 10.1016/j.indmarman.2019.03.015.

Ricciardi, F., Zardini, A. and Rossignoli, C. (2016), "Organizational dynamism and adaptive business model innovation: the triple paradox configuration", Journal of Business Research, Vol. 69 No. 11, pp. 5487-5493, doi: 10.1016/j.jbusres.2016.04.154.

Seiringer, W. (2013), "A rating for customer participation during the process of service co-creation", in Meïr, H. (Ed.), Product-Service Integration for Sustainable Solutions, Springer-Verlag, BerlinHeidelberg, pp. 647-658.

Shimomura, Y. and Akasaka, F. (2013), "Toward product-service system engineering: new system engineering for PSS utilization”, in Meïer, H. (Ed.), Product-Service Integration for Sustainable Solutions, Springer-Verlag, Berlin-Heidelberg, pp. 27-40.

Siggelkow, N. (2007). Persuasion with case studies, Academy of Management Journal, 50(1), 20-24, https://doi.org/10.5465/AMJ.2007.24160882.

Slack, N. (2005), "Operations strategy: will it ever realize its potential?", Gestão and Produção, Vol. 12 No. 3, pp. 323-332.

Story, V., Burton, J., Raddats, C. and Zolkiewski, J. (2015), "Road to nowhere: is servitization really a (transformational) journey from product to pure service provider?", Academy of Marketing Conference, University of Limerick, Limerick, July 7-9.

Sawhney, M., Balasubramanian, S. and Krishnan, V. (2004), "Creating growth with services", MIT Sloan Management Review, Vol. 45 No. 2, pp. 34-43.

Schmitt, R., Schumacher, S. and Zentis, T. (2013), "Quality-oriented risk-management-approach for service innovations", in Meïr, H. (Ed.), Product-Service Integration for Sustainable Solutions, Springer-Verlag, Berlin-Heidelberg, pp. 359-370.

Tukker, A. (2004), “« Eight types of product-service system: eight ways to sustainability Experiences from SusProNet »", Business Strategy and the Environment, Vol. 13 No. 4, pp. 246-60, doi: 10. 1002/bse.414.

Vandermerwe, S. and Rada, J. (1988), "Servitization of business: adding value by adding services", European Management Journal, Vol. 6 No. 4, pp. 314-324, doi: 10.1016/0263-2373(88)90033-3.

Van de Ven, A.H. (2007), Engaged Scholarship: A Guide for Organizational and Social Research Andrew H. Van de Ven, Vernon H Heath Professor of Organizational Innovation and Change Andrew H Van de Ven - Google Livres, Oxford University Press, Oxford, available at: https:// books.google.fr/books?hl=fr\&lr=\&id=2NoTDAAAQBAJ\&oi=fnd\&pg $=$ PR7\&dq $=$ Van + de + Ven,$+2007 \&$ ots $=$ v0sGoeXRbW\&sig $=$ hoT7yMVM0zm8uSsKyARFtdWZgQw\&redir_esc $=y \# v$ $=$ onepage \&q=Van de Ven $\% 2 C$ 2007\&f=false.

Vernadat, F. (2002), “UEML: towards a unified enterprise modelling language”, International Journal of Production Research, Vol. 40 No. 17, pp. 4309-4432.

Vladimirova, D.K. (2012), Transformation of Traditional Manufacturers Towards Servitized Organizations, Cranfield University, Cranfield.

Wang, W., Lai, K.H. and Shou, Y. (2018), "The impact of servitization on firm performance: a metaanalysis", International Journal of Operations and Production Management, Emerald Group Publishing, pp. 1562-1588, doi: 10.1108/IJOPM-04-2017-0204. 
Wang, K., Peng, B. and Jiang, Z. (2018), "Roles of new generation of ICT in servitization of equipment manufacturing: a case study based on four Chinese companies", Zhongguo Jixie Gongcheng/ China Mechanical EngineeringVolume, Vol. 29 No. 18, 25 September 2018, pp. 2259-2267.

Weeks, R. and Benade, S. (2015), "The development of a generic servitization systems framework", Technology in Society, Vol. 43, pp. 97-104.

Woiceshyn, J. (2009), “« lessons from 'good minds': how CEOs use intuition, analysis and guiding principles to make strategic decisions »”, Long Range Planning, Vol. 42 No. 3, pp. 298-319, doi: 10.1016/j.lrp.2009.05.002.

Zambetti, M., Pinto, R. and Pezzotta, G. (2019), "Data lifecycle and technology-based opportunities in new Product Service System offering towards a multidimensional framework", 11th CIRP Conference on Industrial Product-Service Systems, IPS2, 2019, May 2019, Zhuhai-Hong Kong, China.

Zhang, H., Ma, L., Sun, J., Lin, H. and Thürer, M. (2019), "Digital twin in services and industrial product service systems: review and analysis", 11th CIRP Conference on Industrial ProductService Systems, IPS2, 2019, May 2019, Zhuhai-Hong Kong, China.

\section{Further reading}

OMG (2011), "Business process model and notation (BPMN 2.0)", formal/2011-01-03, Object Management Group (OMG), Needham, MA, available at: www.omg.org/spec/BPMN/2.0 (accessed 10 February 2016).

Project Management Institute. (2016), PMBOK Guide | Project Management Institute, (ed.), PMI Global standard, available at: https:/www.pmi.org/pmbok-guide-standards/foundational/pmbok.

Simon, H.A. (1990), "Invariants of human behavior", Annual Review of Psychology, Vol. 41, pp. 1-20.

\section{Corresponding author}

Sarra Dahmani can be contacted at: sarra.dahmani@skema.edu and sarra.dahmani@gmail.com 